\title{
Evaluation of the lower incisor inclination during alignment and leveling using superelastic NiTi archwires: A laboratory study
}

\author{
Carolina Baratieri', Roberto Rocha², Caroline Campos', Luciane Menezes ${ }^{3}$, Gerson Luiz Ulema Ribeiro', Daltro Ritter ${ }^{4}$, Adriano Borgato
}

Objective: The aim of this laboratory study is to evaluate the influence of the shape and the length limitation of superelastic nickel-titanium (NiTi) archwires on lower incisors inclination during alignment and leveling.

Methods: Metal teeth mounted on a typodont articulator device were used to simulate a malocclusion of the mandibular arch (-3.5 mm model discrepancy). Three different shapes (Standard, Accuform and Ideal) of superelastic NiTi archwires (Sentalloy, GAC, USA) were tested. Specimens were divided in two groups: Group I, with no limitation of the archwire length; and Group II, with distal limitation. Each group had thirty specimens divided into three subgroups differentiated by the archwire shape. All groups used round wires with diameters of 0.014-in, 0.016-in, 0.018-in and 0.020-in. The recording of all intervals was accomplished using standardized digital photographs with orthogonal norm in relation to median sagittal plane. The buccolingual inclination of the incisor was registered using photographs and software CorelDraw.

Results: The results were obtained using ANOVA and Tukey's test at a significant level of 5\%. The inclination of the lower incisor increased in both groups and subgroups. The shape of the archwire had statistically significant influence only in Group I - Standard $\left(11.76^{\circ}\right)$, Ideal $\left(5.88^{\circ}\right)$ and Accuform $\left(1.93^{\circ}\right)$. Analyzing the influence of the length limitation, despite the mean incisor tipping in Group II $\left(3.91^{\circ}\right)$ had been smaller than Group I $\left(6.52^{\circ}\right)$, no statistically significant difference was found, except for Standard, $3.89^{\circ}$ with limitation and $11.76^{\circ}$ without limitation. The greatest incisor tipping occurred with the 0.014-in archwires.

Keywords: Arch shape. Superelastic NiTi archwire. Arch length. Incisor tipping.

${ }^{1}$ Specialist in Orthodontics, Federal University of Santa Catarina.

${ }^{2}$ Associate Professor, Department of Orthodontics, UFSC.

${ }^{3}$ Associate Professor, Department of Orthodontics, Pontifical Catholic University of Rio Grande do Sul and UFSC.

${ }^{4} \mathrm{MSc}$ and $\mathrm{PhD}$ in Orthodontics, State University of Rio de Janeiro.

${ }^{5}$ Professor of Computer Science and Statistics, UFSC.
How to cite this article: BBaratieri C, Rocha R, Campos C, Menezes L, Ribeiro GLU, Ritter D, Borgato A. Evaluation of the lower incisor inclination during alignment and leveling using superelastic NiTi archwires: A laboratory study. Dental Press J Orthod. 2012 May-June;17(3):51-7.

Submitted: September 12, 2007 - Revised and accepted: November 21, 2008

" The authors report no commercial, proprietary or financial interest in the products or companies described in this article.

Contact address: Carolina Baratieri

R. Presidente Coutinho, 311 -Salas 1001 a 1004 - Centro - Florianópolis/SC - Brazil Zip code: 88.015-230 - Email: carolinabaratieri@hotmail.com 


\section{INTRODUCTION}

Attention has been focused on the position of the lower incisors in Orthodontic diagnosis and treatment planning because of its effect on aesthetics, periodontal health, long-term stability and even on the space available in the mandibular arch. ${ }^{20}$ In the light of increasing use of fixed appliances, notoriously among adult patients, whenever the planning allows, the option must ensure the preservation of the greatest number of teeth, minimizing the extractions. This treatment option leads to major changes in the buccolingual inclination of the lower incisors, which results in greater care in the diagnosis of the final incisor position and in the treatment plan execution.

Nickel-titanium (NiTi) wires were introduced to the market in the late 70's. Later in the 80's, were launched the superelastic NiTi archwires and in the 1990s the superelastic thermal-activated NiTi. ${ }^{9}$ The superelastic NiTi archwires have been proposed for the initial phase of alignment, because of its unique property of memory and superelasticity. ${ }^{14}$

Maintaining patient's original arch form during the orthodontic treatment is recognized essential to achieve long-term stability. ${ }^{6,10,11,21}$ The major disadvantage of NiTi archwires is the lack of formability, ${ }^{18}$ which doesn't allow conforming the orthodontic archwire under the patient's arch. Different shapes of pre-contoured archwires have been introduced, enabling the practitioner to select the arch according to the patient's at the beginning of the treatment.

With the convenience and popularity of superelastic NiTi archwires, its indiscriminate use has increased, leading to the questioning of two fundamental orthodontics principles: maintaining patient's original arch form (stability) and labial inclination of the teeth (periodontal health).

Numerous studies ${ }^{6,8,11,21}$ have been conducted on the changes of mandibular arch, especially the lower incisors, in order to quantify the effects on the stability and periodontal health. These changes can be easily detectable and measurable, however, it is difficult to correlate them because of the innumerous variables present in a clinical study, such as the malocclusion, orthodontic mechanics, sex, gender, duration of treatment. Based on this premise, the present study was conducted using a Typodont simulator with standardized malocclusion, testing two variables, the shape and the length limitation of the NiTi archwires.

The purpose of this laboratory study is to evaluate the influence of the shape and the limiting of the length of superelastic NiTi archwires on the lower incisors inclination during the alignment and leveling.

\section{MATERIAL AND METHODS}

Metal teeth mounted on a Typodont articulator (3M/Unitek, 611-500), previously banded with brackets slot $0.022 \times 0.028$-in (Morelli, Edgewise/Standard - 10.30.901) was used to simulate the lower arch malocclusion. The left lower central incisor, additionally received the establishment of a steel wire segment (0.019 x 0.025-in and length of $2 \mathrm{~cm}$ ) parallel to the long axis of the tooth crown, distally to the bracket (Fig 3 ). This procedure allowed the registration of the incisor buccolingual inclination at all stages of the alignment. The teeth were mounted with a discrepancy of -3.5 mm (Fig 1E) and absence of Spee curve (Fig 3).

A condensation silicone (Resi-Line Commercial LTD) impression was performed on the lower arch simulated. After that, the metal teeth could be repositioned, allowing the 60 times malocclusion replication needed (Fig 1 ).

Three different shapes of pre-contoured superelastic NiTi archwires (Sentalloy - Psychic Force Mandibular Arch, GAC Inc) were tested (Fig 2). The sample was divided into 2 groups: Group I, without distal limitation on the length of the archwire and Group II, limiting the length of the archwire with a distal bend (Fig 3). Each group was composed of 30 specimens that were divided into three subgroups according to the shape of the archwire: 10 Standard (Code 02-510-6), 10 Accuform (code 02-511-6) and 10 Ideal (code 02-517-6). In all 60 replicated malocclusions were used a sequence of round continuous archwires 0.014-in, 0.016-in, 0.018-in and 0.020-in for the alignment and leveling of the teeth.

Elastomeric rings (59-100-70, GAC) were used to tie the archwire. The only difference between groups I and II was limiting or not the archwire length (Fig 1). In Group I, the archwires were let free after the second molar tube and in Group II, the archwires were previously heated at each end for 5 seconds with a Blazer (Blazer Products Inc.), 

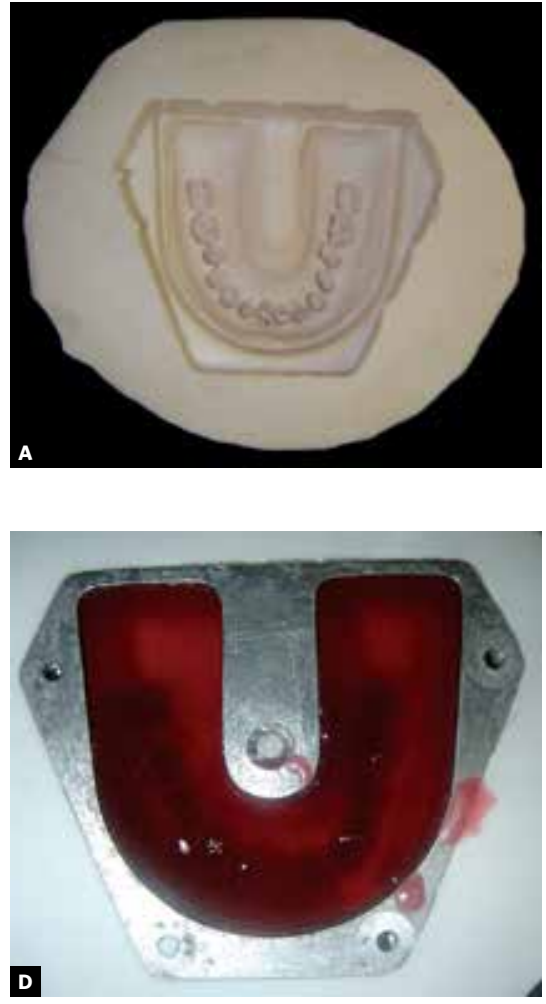
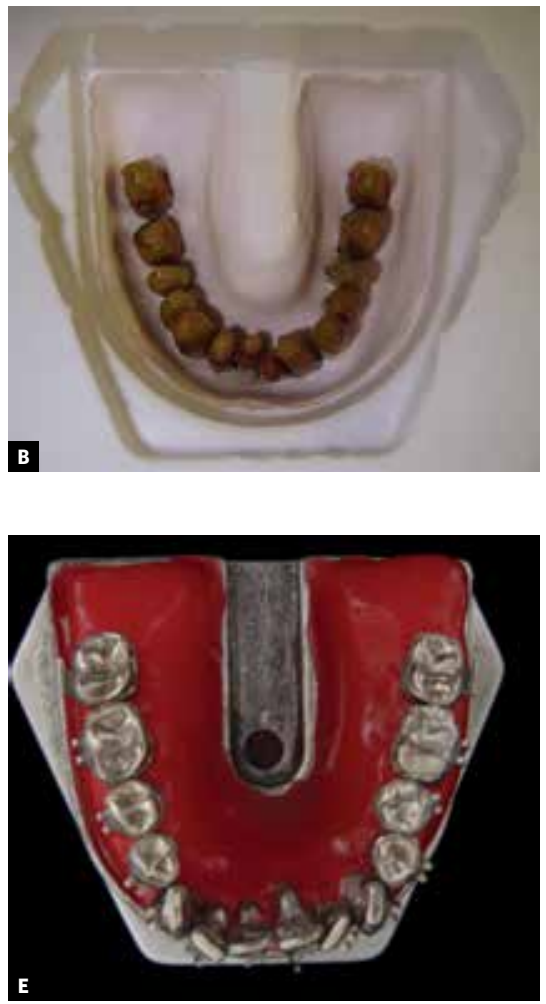

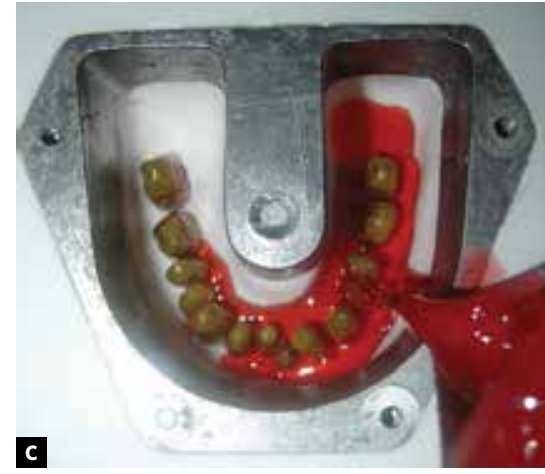

Figure 1 - Sequence of procedures used to obtain the standardized samples $(n=60)$ : A) Silicon mold of initial malocclusion; B) positioning the teeth in metallic mold; $\mathbf{C}$ ) insertion of plastified wax; D) set of mold, teeth, metallic support and wax; E) final obtaining of standardized sample.

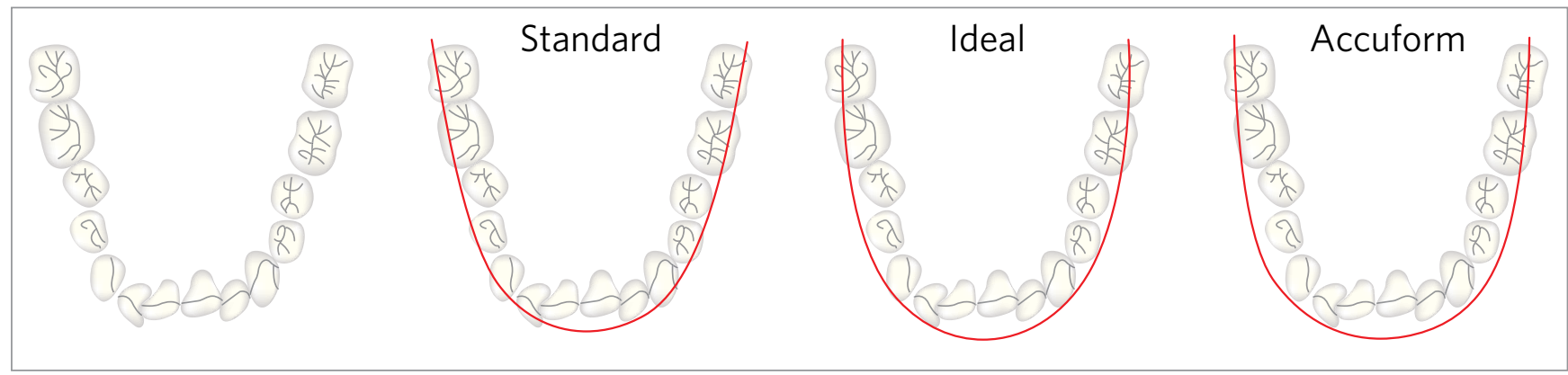

Figure 2 - Illustration of pre-contoured archwires shapes used.
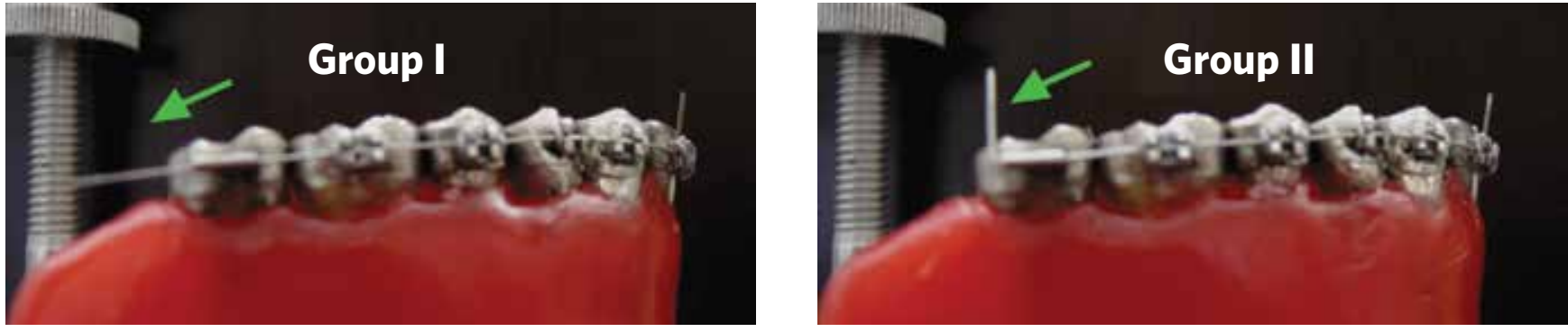

Figure 3 - Segment of steel wire was added parallel to the long axis of the crown of the left central incisor. The green arrow indicates the difference between groups: Group I, the length of the arch was not limited; Group II, there was limitation on arch length. 
insert into the tube and bent distally with a special instrumental (Morelli, 75.02.022). The typodont was then immersed in warm water $\left(50^{\circ} \mathrm{C}\right)$, controlled by thermostat, and tooth movement was possible (Fig 4). Two immersions were realized for each archwire diameter. The immersion time was standardized for 4 minutes at $50^{\circ} \mathrm{C}$ with 30 -second interval between them in water at $25^{\circ} \mathrm{C}$.

The record of all stages (initial, 0.014-in, 0.016in, 0.018-in and 0.020-in) was realized by means of digital photos (Sony/Cybershot 5.1 MP) standardized in orthogonal norm to the midsagittal plane
(Figs 5 and 6). It was obtained a total of 300 photographs (60 samples x 5 stages records).

The inclination of the lower incisor was measured on the photographs using the software Corel Draw, version 13 (Fig 6). After realized and collected all the measurements the ANOVA test was performed to determine the behavior of the groups. It was tested the differences among the shapes of the archwires, the length limitation and the interaction between them. A subsequent Tukey's post hoc test was used to identify intra-group and intergroup statistical significant differences $(p<0.05)$.

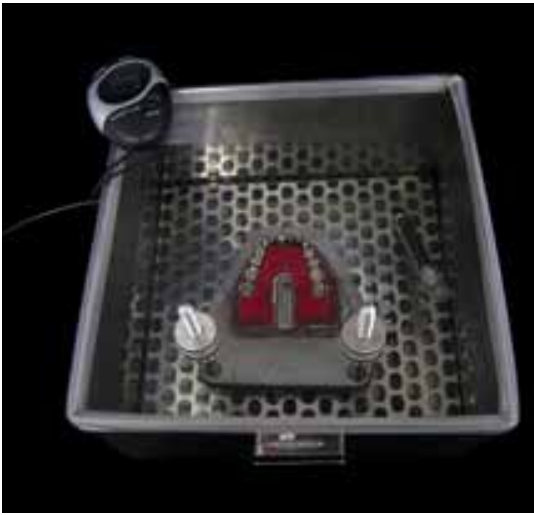

Figure 4 - Simulator submerged in warm water $\left(50^{\circ} \mathrm{C}\right)$ controlled by a thermostat and a timer to allow tooth movement.
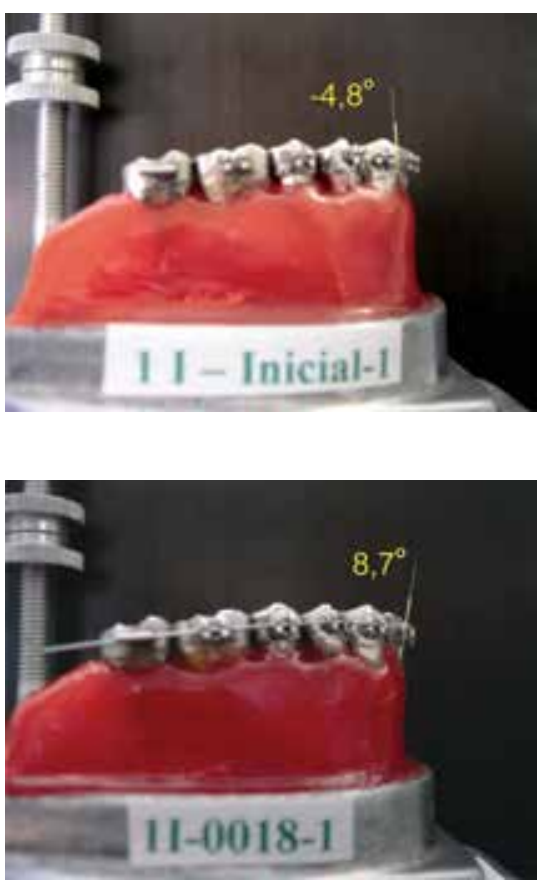

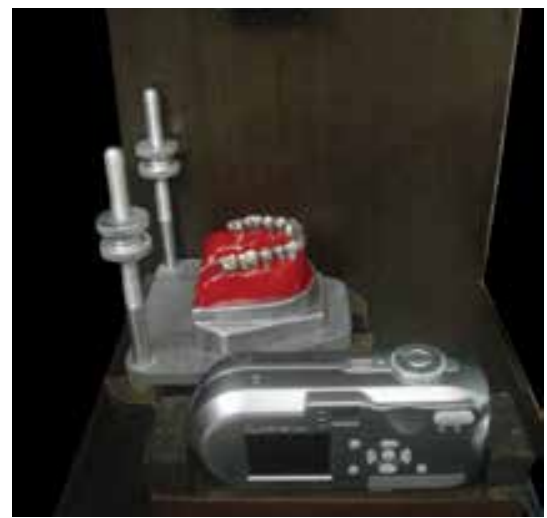

Figure 5 - Wooden device to standardize the registration of the phases (initial, 0.014-in 0.016 -in, 0.018 -in and 0.020 -in) by means of digital photographs in the orthogonal norm to the sagittal plane.
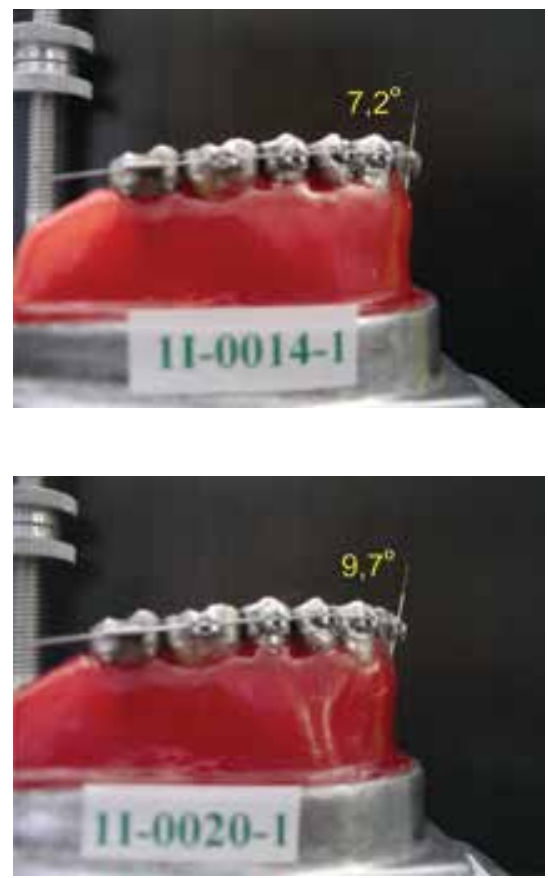

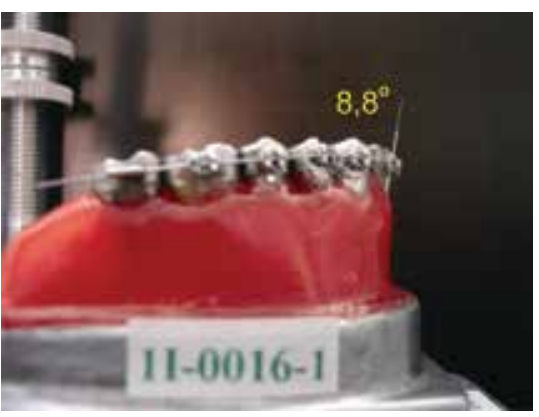

Figure 6 - Sequence of photographs to obtain lower incisor tipping at all stages (initial, 0.014-in, 0.016-in, 0.018-in and 0.020-in). 


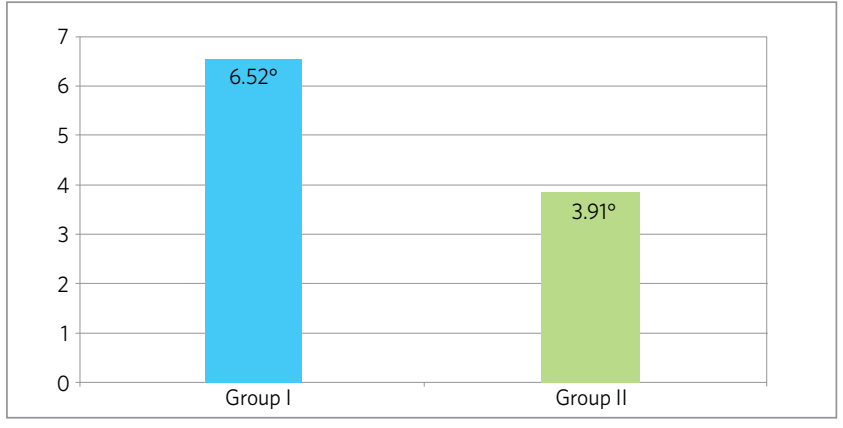

Figure 7 - Mean inclination of the lower incisor (degrees)
Table 1 - Mean difference between the final and the initial position (degrees) of the lower incisor (ANOVA).

Difference between initial and final inclination of the lower incisor

\begin{tabular}{cccc} 
Binding & Standard & Ideal & Accuform \\
Group I & $11.76^{\mathrm{aA}}$ & $5.88^{\mathrm{bA}}$ & $1.93^{\mathrm{cA}}$ \\
Group II & $3.89^{\mathrm{aB}}$ & $3.54^{\mathrm{aA}}$ & $4.29^{\mathrm{aA}}$ \\
\hline
\end{tabular}

Same lower-case letter $(a, b, c)$ in the same row represents similarity $(p>0.05)$ among the means.

Same caps letter (A, B) in the same column represents similarity $(p>0.05)$ between the means.

Table 2 - Mean inclination of the lower incisor during the tested intervals in the different subgroups (Tukey's test).

\begin{tabular}{|c|c|c|c|c|}
\hline Subgroups & \multicolumn{4}{|c|}{ Intervals } \\
\hline Group / Archwire shape & 0.014-in - Initial & 0.016 -in -0.014 -in & 0.018 -in -0.016 -in & 0.020 -in -0.018 -in \\
\hline Group I / Standard & $7.45^{\mathrm{a}}$ & $1.02^{b}$ & $1.14^{b}$ & $2.15^{b}$ \\
\hline Group I / Ideal & $7.43^{a}$ & $-0.15^{b}$ & $-1.19^{b}$ & $-0.21^{b}$ \\
\hline Group I / Accuform & $3.81^{\mathrm{a}}$ & $-0.77^{b}$ & $-0.16^{b}$ & $-0.95^{b}$ \\
\hline Group II / Standard & $3.91^{\mathrm{a}}$ & $0.74^{b}$ & $-1.00^{b}$ & $0.24^{b}$ \\
\hline Group II / Ideal & $3.93^{\mathrm{a}}$ & $-0.34^{a}$ & $-0.40^{a}$ & $0.49^{a}$ \\
\hline Group II / Accuform & $4.48^{a}$ & $0.27^{b}$ & $-0.62^{b}$ & $-0.27^{b}$ \\
\hline
\end{tabular}

Same lower-case letter $(a, b)$ in the same row represents similarity $(p>0.05)$ among the means.

\section{RESULTS}

Buccolingual inclination of the incisor increased in both groups regardless of the archwire shape and limited or not the archwires length (Table 1). The mean inclination of the lower incisors in Group I (without limitation) was $6.52^{\circ}$ and in Group II (with limitation) was $3.91^{\circ}$, however, this difference was not statistically significant (Fig 7).

When the archwire shapes were evaluated, the Group I (without limitation) showed mean inclination of the lower incisor increased of $11.76^{\circ}, 5.88^{\circ}$ and $1.93^{\circ}$, respectively to the Standard, Ideal and Accuform. However, in Group II (with limitation) the increase of the incisor inclination was not statistically significant among the archwire shapes (Standard $=3.89^{\circ}, 3.54^{\circ}=$ Ideal; Accuform $=4.29^{\circ}$ ). Analyzing individually the limitation or not of the archwire length, the only statistically significant difference was with the Standard shape (with limitation $=3.89^{\circ}$; without limitation $\left.=11.76^{\circ}\right)($ Table 1$)$.

Table 2 showed that in all subgroups the greatest change in the inclination occurred after the use of 0014-in archwire, except for the subgroup Ideal with limitation that showed no statistically significant difference among the different archwires diameter.

\section{DISCUSSION}

This study showed that regardless of the shape and length of the archwires used the buccolingual inclination of the incisors increased. This suggests that when there is lack of space in the lower arch, alignment and leveling using superelastic NiTi archwires causes labial tipping ofw the lower incisors. In a clinical study using lateral cephalometric radiographs, Pandis, Polychronopoulou and Eliades ${ }^{17}$ also found increased of the labial inclination of the mandibular incisors during the leveling of lower arch when a lack of space was observed, regardless of the bracket system used.

The effect of lower incisors labial tipping on the periodontium remains controversial. While Little, Riedel and Stein ${ }^{13}$ showed association between gingival recession and labial movement of the incisors, other authors did not found association. ${ }^{1,719}$ Yared, Zenobio and Pacheco ${ }^{24}$ evaluated the periodontal condition of lower incisors moved labially during orthodontic treatment and found no correlation between proclination and gingival recession. They also concluded that greater incisor tipping is acceptable, reducing the risk of periodontal damage, when the incisors are not proclined in the beginning of the treatment, so the incisor position at the end of the treatment is more important 
than the tipping amount during the treatment. Djeu, Hayes and Zawaidesh ${ }^{7}$ also found no correlation, however, they underline the importance of determining how much tipping could be achieved with fixed appliances before gingival recessions begin to appear.

The indiscriminate use of pre-contoured archwires during alignment can cause damage to the patients, as comes to facial aesthetics, periodontal health and even compromising the stability of the treatment. Thus, a careful evaluation to obtain an accurate diagnosis and treatment plan must be prior established to determine when it is possible and necessary to tip the incisors buccally and when this should be avoided.

In cases of severe overjet and anterior crowding, lower incisors proclination can be a valuable alternative to avoid extraction, particularly in critical facial profile cases. ${ }^{16}$ Artun and Grobéty ${ }^{3}$ concluded that pronounced advancement of the mandibular incisors may be performed in Class II adolescent patients with dentoalveolar retrusion without increasing the risk of recession. Increased proclination may also be a treatment option of presurgical orthodontic decompensation on lower incisor inclination in Class III patients undergoing for mandibular orthognathic surgery. It was reported that adults patients who required more than $10^{\circ}$ of lower incisor proclination during the presurgical decompensation, this expansion was accompanied by significant risk of gingival recession, especially when the alveolar process was thin. ${ }^{3}$

Both, the lack of difference in the long-term stability among extraction and non-extraction $\operatorname{cases}^{8}$ and the fact that clinical measurements undertaken in mandibular orthognathic surgical patients showed no association between incisor inclination and long-term incisor irregularity ${ }^{2}$ have further weakened the argument against proclination.

It is unknown the amount of crowding that can be solved with teeth inclination and/or expansion and that would be still considered stable. Tanaka, Ribeiro and Mucha, ${ }^{22}$ in a literature review on the importance of the maintenance of the lower arch form, found considerable controversy on dental expansion. It is said that the shape of the patient original lower arch seems is the best guide for long-term stability. However, even minimizing changes during the treatment there is no stability guarantee. ${ }^{6}$ In cases where incisor inclination and/or expansion are required, the use of permanent retainer could be an option to the lower anterior alignment maintenance, ${ }^{12,13}$

There is a range of arch shapes within population, ${ }^{5,15}$ The literature reported that the main shapes found in untreated individuals are tapered, ovoid and average. ${ }^{4,23}$ According to Taner et al ${ }^{23}$ most of mandibular arches shows tapered shape before orthodontic treatment. In our study, the format standard was the most similar to the malocclusion arch simulated. The results showed that the greatest labial tipping of the incisors occurred when the shape standard was used. This result showed that only choose the most closely arch wire shape does not mean that the lower incisors will not be affected, so it is important to underline that the choice or construction of the arch wire according to the original patient dimensions (intercanine and intermolar) does not exclude the need of an accurate diagnosis and detailed treatment plan to achieve the desirable incisor position.

The archwire shape influenced statistically significant the incisor inclination in Group I (Table 1). The incisors have the highest labial tipping with the Standard shape and the lowest with the Accuform. Comparing the both shapes (Fig 2), it is possible to note that the Standard shows the intercanine region more contracted, while the Accuform, this same region, is more expanded. This may have allowed further expansion in the canines region and lower labial inclination of the incisor during alignment.

Another important finding in this study was that the greatest amount of incisor tipping occurred in the first phase of the alignment and leveling with the 0.014-in archwires, regardless of the shape and the length. This suggests that when no incisor proclination is desired, care must be taken from the first archwire used for the alignment and leveling.

It is believed that the length limitation of the archwire, distal bending or tying, prevents the incisor proclination. However, this fact is based on clinical experience and not scientific based, because the literature is still scarce on this topic. In our study, both groups showed labial inclination of the incisors. Despite the mean inclination of the lower incisors had been lower in the Group II (with limitation), this difference was not statistically significant.

Clinical studies are suggested to test the effectiveness of the archwire length limitation on 
incisor proclination. The method used was not efficient in this study, because even limiting the archwire length, labial inclination occurred. The distal bend realized did not prevent the slippage of the archwire during the alignment and labial inclination of the incisors occurred. Thus, when labial tipping is not required another method should be taking into account during the planning of the case.

\section{CONCLUSION}

According to the methods it can be concluded that: » Lower incisors tipped buccally regardless of the shape and the length of the superelastic NiTi archwires used.
»Despite the mean incisor labial inclination found using archwires with length limitation (Group II) was lower than no limitation arch wires (Group I), no statistical difference was found.

» Superelastic NiTi archwire shape only showed significant influence on the final inclination of the incisor when the arch wires were not distal limited.

» The highest proclination of the incisor occurred when the Standard archwires were used.

» Regardless of shape and length, the higher degree of incisor inclination occurred in first stage of the alignment and leveling.

\section{REFERENCES}

1. Allais D, Melsen B. Does labial movement of lower incisors influence the level of the gingival margin? A case-control study of adult orthodontic patients. Eur J Orthod. 2003 Aug;25(4):343-52.

2. Artun J, Krogstad O, Little RM. Stability of mandibular incisors following excessive proclination: a study in adults with surgically treated mandibular prognathism. Angle Orthod. 1990 Summer;60(2):99-106.

3. Artun J, Grobéty D. Periodontal status of mandibular incisors after pronounced orthodontic advancement during adolescence: A follow-up evaluation. Am J Orthod Dentofacial Orthop. 2001 Jan;119(1):2-10.

4. Braun S, Hnat WP, Leschinsky R, Legan HL. An evaluation of the shape of some popular nickel-titanium alloy preformed arch wires. Am J Orthod Dentofacial Orthop. 1999 Jul;116(1):1-12.

5. Cassidy KM, Harris EF, Tolley EA, Keim RG. Genetic influence on dental arch form in orthodontic patients. Angle Orthod. 1998 Oct;68(5):445-54.

6. de la Cruz A, Sampson P, Little RM, Artun J, Shapiro PA Long-term changes in arch form alter orthodontic treatment and retention. Am J Orthod Dentofacial Orthop. 1995 May;107(5):518-30.

7. Djeu G, Hayes C, Zawaideh S. Correlation between mandibular central incisor proclination and gingival recession during fixed appliance therapy. Angle Orthod. 2002 Jun;72(3):238-45.

8. Gardner SD, Chaconas SJ. Posttreatment and Postretention Changes following Orthodontic Therapy. Angle Orthod. 1976 Apr;46(2):151-61.

9. Gurgel JA, Ramos AL, Kerr SD. Fios ortodônticos. Dental Press, 2001;6(4):103-4

10. Housley JA, Nanda RS, Currier GF, McCune DE. Stability of transverse expansion in the mandibular arch. Am J Orthod Dentofacial Orthop. 2003 Sep;124(3):288-93.

11. Little RM, Riedel RA, Artun J. An evaluation of changes in mandibular alignment from 10 to 20 years postretention. Am J Orthod Dentofacial Orthop. 1988 May;93(5):423-8.

12. Little RM, Wallen TR, Riedel RA. Stability and relapse of mandibular anterior alignment - first premolar extraction cases treated by traditional edgewise orthodontics. Am J Orthod. 1981 Oct;80(4):349-65.
13. Little RM, Riedel RA, Stein A. Mandibular arch length increase during the mixed dentition: Postretention evaluation of stability and relapse. Am J Orthod Dentofacial Orthop. 1990 May;97(5):393-404

14. Mallory DC, English JD, Powers JM, Brantley WA, Bussa HI. Force-deflection comparison of superelastic nickel-titanium archwires. Am J Orthod Dentofacial Orthop. 2004 Jul;126(1):110-2.

15. Noroozi H, Nik TH, Saeeda R. The Dental Arch Form Revisited. Angle Orthod. 2001 Oct;71(5):386-9. Erratum in: Angle Orthod 2001 Dec;71(6):525

16. Melsen B, Allais D. Factors of importance for the development of dehiscences during labial movement of mandibular incisors: A retrospective study of adult orthodontic patients. Am J Orthod Dentofacial Orthop. 2005 May;127(5):552-61; quiz 625.

17. Pandis N, Polychronopoulou A, Eliades T. Self-ligating vs conventional brackets in the treatment of mandibular crowding: A prospective clinical trial of treatment duration and dental effects Am J Orthod Dentofacial Orthop. 2007 Aug;132(2):208-15.

18. Proffit WR, Fields Junior HY. Princípios mecânicos no controle da força ortodôntica. In: Ortodontia contemporânea. 3a ed. Rio de Janeiro (RJ): Guanabara Koogan; 2002. p.307-339.

19. Ruf S, Hansen K, Pancherz H. Does orthodontic proclination of lower incisors in children and adolescents cause gingival recession? Am J Orthod Dentofacial Orthop. 1998 Jul;114(1):100-6.

20. Schulhof RJ, Allen RW, Walters RD, Dreskin M. The mandibular dental arch: Part I, Lower Incisor Position. Angle Orthod. 1977 Oct;47(4):280-7.

21. Shapiro PA. Mandibular dental arch form and dimension: treatment and postretention changes. Am J Orthod. 1974 Jul;66(1):58-70.

22. Tanaka OM, Ribeiro GLU, Mucha JN. A importância da manutenção da forma do arco mandibular no tratamento ortodôntico. Parte 1: revisão. Rev SBO, 1999; 3(8):323-9.

23. Taner TU, Ciger S, El H, Germeç D, Es A. Evaluation of dental arch width and form changes after orthodontic treatment and retention with a new computerized method. Am J Orthod Dentofacial Orthop. 2004 Oct;126(4):464-75; discussion 475-6.

24. Yared KF, Zenobio EG, Pacheco W. Periodontal status of mandibular central incisors after orthodontic proclination in adults. Am J Orthod Dentofacial Orthop. 2006 Jul;130(1):6.e1-8. 